\title{
Reduzir o tempo de disponibilização pelo médico da documentação completa para a alta
}

Belt: Glaucia Mayumi Hayama Menezes da Silva e Gestora: Nilsa Mara de Arruda Yamanaka

Alinhamento estratégico: Melhorar/Reduzir o tempo médico para disponibilizar os documentos de alta para enfermagem e otimizar o tempo final de alta da liberação do paciente.

\section{Considerações Iniciais:}

Problema: Atraso da equipe médica em realizar a alta em sistema e disponibilizar os documentos de alta para a enfermagem.

\section{Meta e Objetivo:}

Médico realizar a alta e Enfermagem receber a documentação de alta pelo médico.

Meta: Redução de $50 \%$ do tempo de alta médica 40 minutos.

\section{Estado Antes do Projeto:}

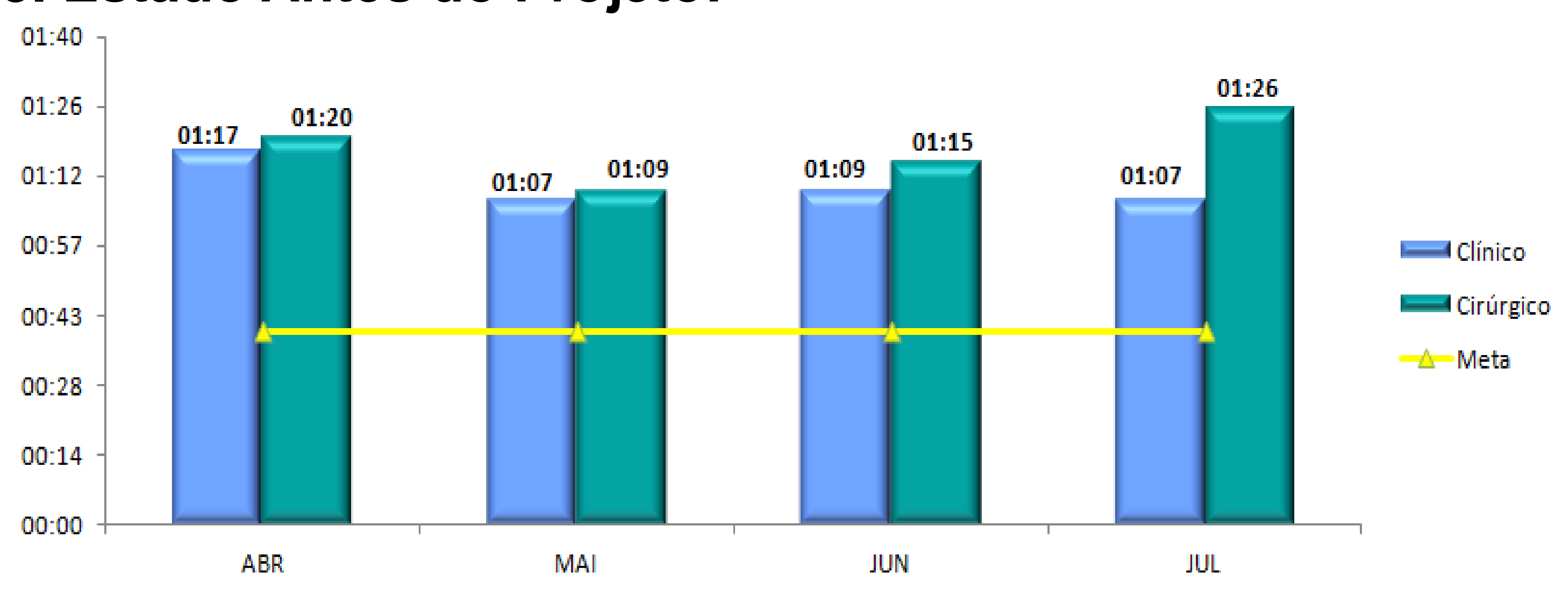

\section{Análise:}

Após a realização do Ishikawa, foi elaborado a Matriz de Causa e Efeito e de Esforço x Impacto para identificarmos as causas e atuar com ações estratégicas para melhorar/ mitigar as causas que impactam no tempo da alta médica.

Mediante a análise, definiu as causas a serem atuadas:

- Gerar alta no Centro Cirúrgico;

- Gerar alta na Sala dos Residentes;

- Médico entregar documentação para enfermeiro após o término da cirurgia;

- Médico entregar documentação após realização das altas na Sala dos Residentes.

\section{Estado Após Projeto:}
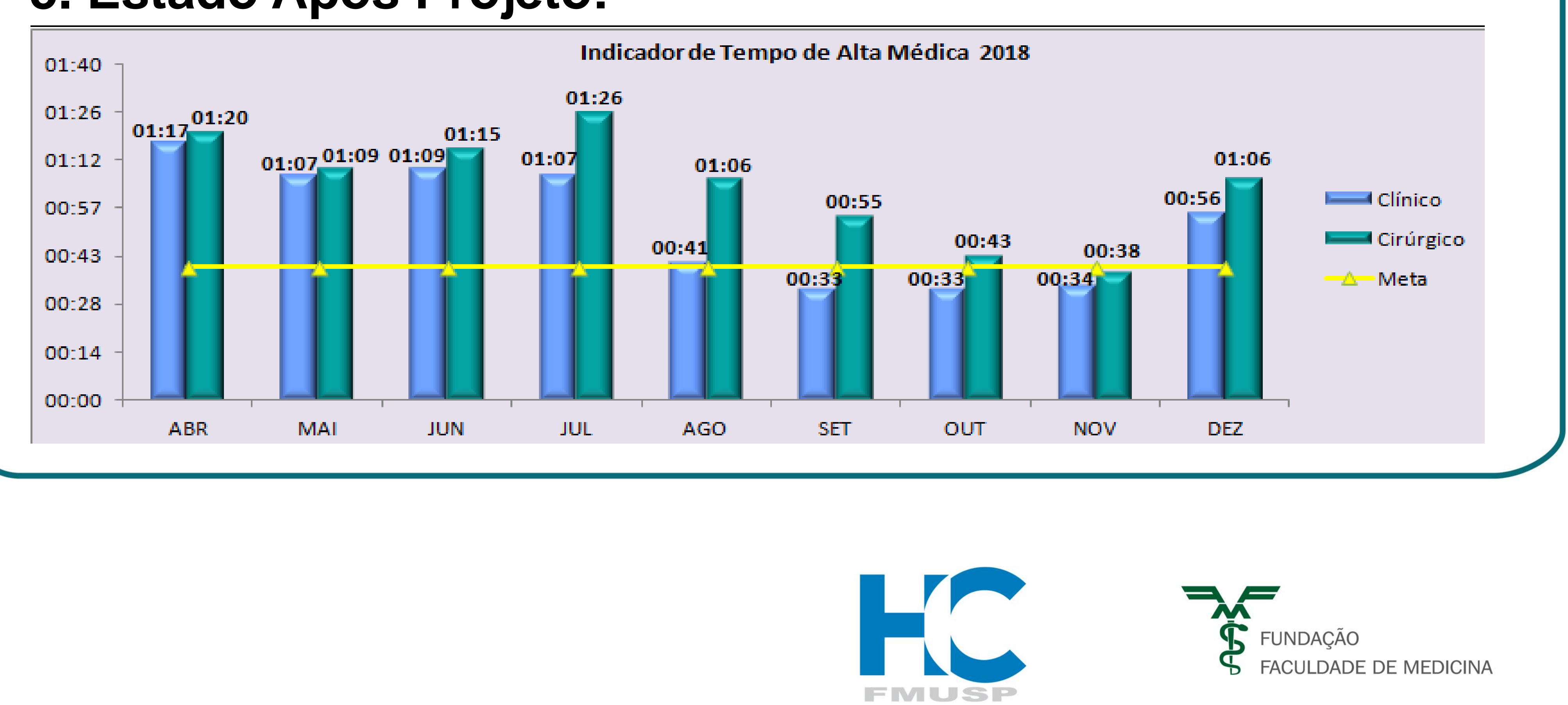

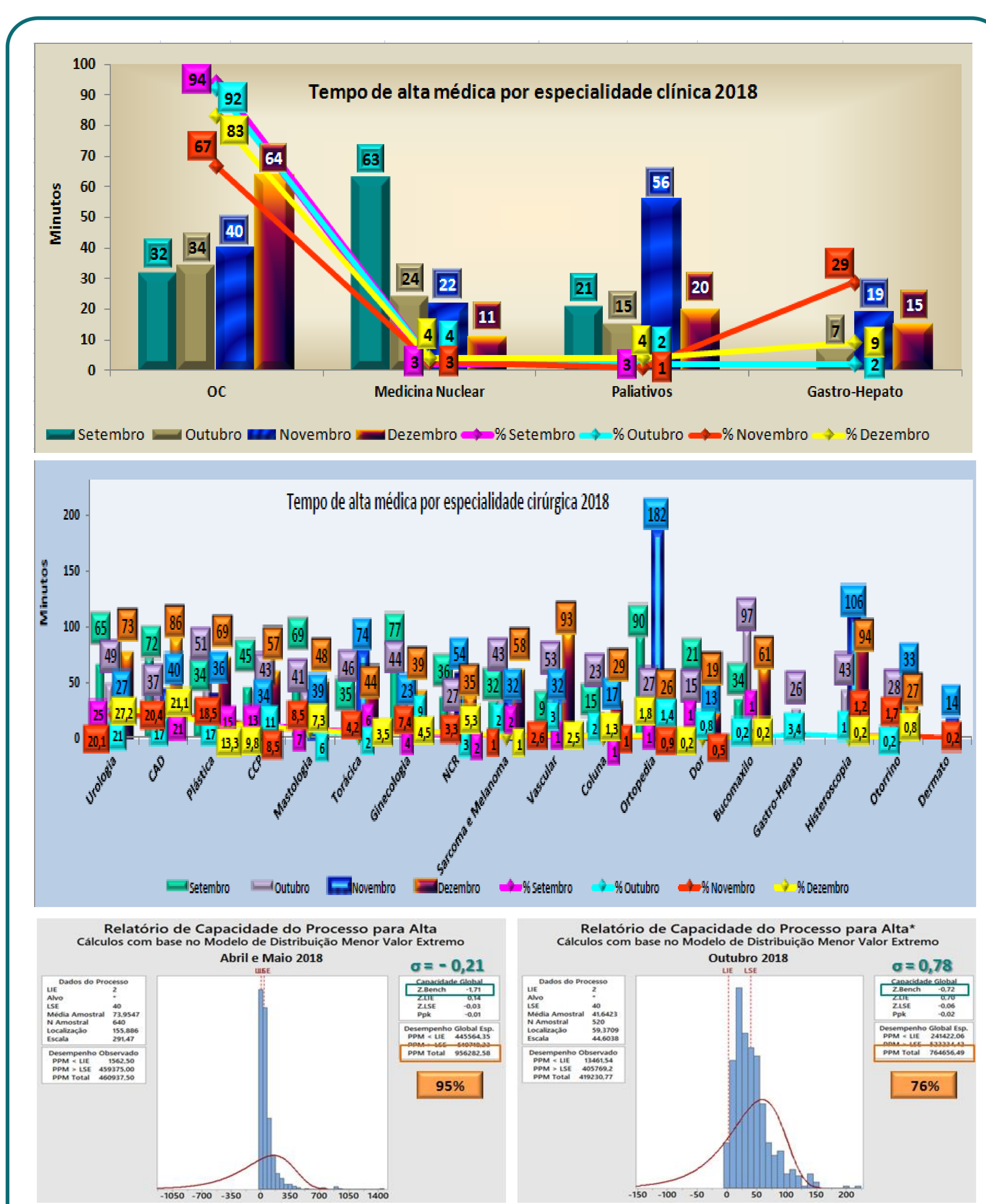

\section{Plano de Melhoria:}

\begin{tabular}{|c|c|c|}
\hline Ação & Responsável & Status \\
\hline $\begin{array}{l}\text { Médico gerar e liberar alta médica em Sistema Tasy e } \\
\text { Enfermeiros da Unidade de Internação imprimir os }\end{array}$ & Glaucia & Concluído \\
\hline
\end{tabular}
documentos e iniciar o processo de alta do paciente.

\section{Plano de Controle:}

Forma de Controle Frequência Responsável Plano de Reação \begin{tabular}{l|l|l} 
Realizar o acompanhamento & Reorientar a equipe
\end{tabular} das especialidades médicas Mensal GEFIP médica e enfermagem por meio do Indicador de Mensal GEFIP que estiver desviando Tempo de Alta Médica da meta estabelecida 